\title{
Correction to: Eye Movement Desensitization and Reprocessing in Child and Adolescent Psychology: a Narrative Review
}

Cristina Civilotti ${ }^{1,2, *}$

Davide Margola ${ }^{3}$

Maria Zaccagnino 4

Martina Cussino ${ }^{4}$

Chiara Callerame $^{4}$

Alessia Vicini $^{1}$

Isabel Fernandez $z^{5}$

\section{Address}

${ }^{1}$ Department of Psychology, University of Turin, Turin, Italy

${ }^{*}, 2$ Salesian University Institute of Torino Rebaudengo (IUSTO), Turin, Italy

Email: cristina.civilotti@unito.it

${ }^{3}$ Faculty of Psychology, Catholic University of Milan, Milan, Italy

${ }^{4}$ Center of EMDR Therapy for Eating Disorders, Milan, Italy

${ }^{5}$ Centro di Ricerca e Studi in Psicotraumatologia (C.R.S.P.), Milan, Italy

Published online: 3 August 2021

(C) Springer Nature Switzerland AG 2021

The online version of the original article can be found at https://doi.org/10.1007/s40501-021-00244-0

Correction to: Curr Treat Options Psych

http://doi.org/10.1007/s40501-021-00244-0

The original publication of this article contained mistakes and the author would like to correct them. There is an error in the affiliation of author Isabel Fernandez.

Isabel Fernandez is not affiliated to Catholic University. She is only affiliated to "Centro di Ricerca e Studi in

Psicotraumatologia (C.R.S.P.), Milan, Italy."

The original article has been corrected.

\section{Publisher's Note}

Springer Nature remains neutral with regard to jurisdictional claims in published maps and institutional affiliations. 